\title{
UNA SEPULTURA DE INCINERACIÓN DEL TÚMULO E DE SETEFILLA*
}

\section{A CREMATION BURIAL FROM SETEFILLA'S MOUND 7}

\author{
MARÍA EUGENIA AUBET**
}

Resumen: El hallazgo de nuevos materiales y sepulturas en el área de la necrópolis de Setefilla muestra que la estructura compleja y jerárquica de los túmulos A y $\mathrm{B}$ excavados en los años 70 constituyó un rasgo característico de este importante conjunto funerario. La identificación de útiles y armas de la Edad del Bronce sugiere, además, un uso continuo de la zona de los túmulos desde mediados /finales del $2^{\circ}$ milenio a.C. Palabras claves: prácticas funerarias, incineraciones, metalurgia tartésica.

Durante el mes de septiembre de 1981 y como consecuencia de trabajos de ampliación y consolidación de la carretera de Lora del Río a la Mesa de Setefilla, fueron descubiertos los restos de una sepultura de incineración en la necrópolis de túmulos de Setefilla. La sepultura fue recuperada por el Sr. Blas Cosano en el borde septentrional de un pequeño túmulo funerario, apenas visible sobre el terreno y situado en el sector norte de la necrópolis. ${ }^{1}$

\footnotetext{
* Este artículo fue redactado hace unos años para el volumen de homenaje al Profesor Juan Maluquer de Motes. Los originales se perdieron y dicho volumen no llegó a ser publicado. Recientemente se halló por casualidad una copia de dicho artículo, de cuyo texto original hemos sacado este extracto, eliminando y añadiendo algunos párrafos. Queremos agradecer a Ramón Álvarez el esfuerzo que ha invertido en recuperar los dibujos originales a partir de copias en mal estado. Desde estas líneas queremos expresar también nuestro más sincero agradecimiento a Concha Blasco, Marisa Ruiz-Gálvez y Eduardo Galán por sus indicaciones y por su valiosa información durante la revisión y elaboración final de este trabajo.

** Departamento de Humanidades, Univeritat Pompeu Fabra
}

Abstract: The finding of new grave goods and burials in the cemetery area of Setefilla shows that the complex and hierarchical structure of tumuli A and B excavated in the seventies was a characteristic feature of this important funerary group. The identification of Bronze Age tools and arms suggest, also, a continuity in the use of the tumuli area from the middle/second half of the second millennium B.C.

Key words: mortuary practices, cremations, tartessian metallurgy.

El hallazgo corresponde a la zona del denominado Túmulo E de la nomenclatura utilizada por los primeros excavadores del yacimiento, en 1926-27 (Bonsor \& Thouvenot 1928:12, fig.4). El pequeño túmulo E está situado al sur de la carretera que divide en dos la necrópolis (fig. 1) y en las proximidades del Túmulo B, excavado en 1975 (Aubet 1978). A juzgar por los materiales recuperados y por los vestigios de cenizas y huesos quemados observados en el momento del descubrimiento, es evidente que los materiales formaron parte de un enterramiento de incineración muy similar a los hallados en la base de los Túmulos A y B. De ser así, tendríamos en el Túmulo $\mathrm{E}$ un nuevo ejemplo de círculo funerario conteniendo un número relativamente elevado de incineraciones en la base del monumento.

El Túmulo E fue explorado por Bonsor y Thouvenot durante los años 1926-27, sin proporcionar hallazgos significativos. Solamente en el centro del túmulo se localizó una fosa de $1 \mathrm{~m}^{2}$, vacía y cubierta por grandes losas de piedra, semejantes a las de una estructura dolménica (Bonsor \& Thouvenot 1928:16, fig.9). 


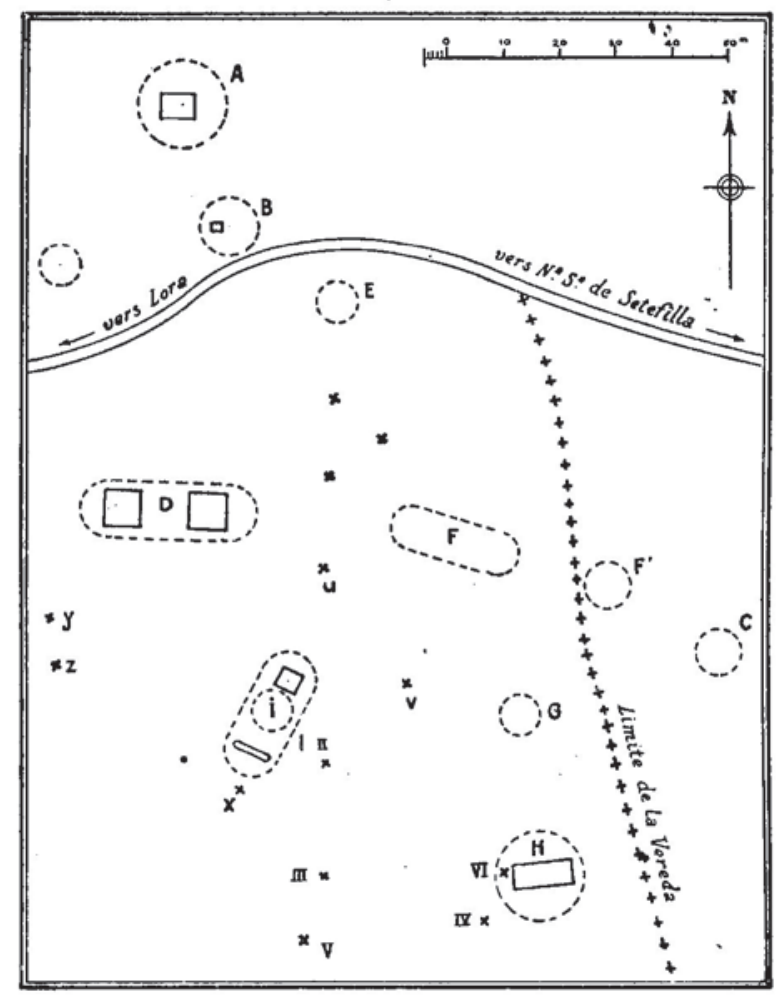

Figura 1. Plano de la necrópolis de Setefilla (según Bonsor \& Thouvenot 1928)

La losa de cobertura medía $2 \mathrm{~m}$ de longitud y la cista había servido, al parecer, para contener una inhumación. Los excavadores del Túmulo $\mathrm{E}$ hacen notar que la cista parecía extraña al contexto general del túmulo, sin que sepamos con exactitud porqué. En la publicación de 1928 no se dan detalles acerca de la disposición exacta de este enterramiento central en relación a la estructura tumular, por lo que ignoramos si se trata de una fosa revestida de lajas y practicada en el nivel de base del túmulo o bien de un enterramiento intrusivo y tardío.

Con los datos disponibles del Túmulo E resulta muy difícil establecer un diagnóstico del monumento funerario en cuestión. Consta solamente que la losa de cobertura de la cista central "apareció a los primeros golpes de pico", es decir, muy cerca de la superficie del túmulo. La experiencia nos ha enseñado que la inmensa mayoría de los túmulos de Setefilla se excavó en 1926-27 siguiendo el método de perforar la parte central de los túmulos. Lo que ha originado no pocas confusiones a la hora de intentar una lectura correcta de los datos arqueológicos. Sirva de ejemplo el Túmulo B, considerado una estructura destinada a contener una sola incineración en el centro (Bonsor \& Thouvenot 1928: 14, fig.6) y que resultó ser un monumento sumamente complejo que albergaba hasta 33 incineraciones (Aubet 1978).

El hallazgo de 1981 pone de manifiesto la posibilidad de que en la base del Túmulo E existiera otro "círculo" de incineraciones dispuestas en torno a una inhumación central y de carácterísticas muy similares a las observadas en los Túmulos A y B, en los que se ha identificado un centenar de incineraciones. No hay que descartar, sin embargo, la posibilidad de que en el área de la necrópolis de túmulos del Hierro existieran enterramientos más antiguos, parcialmente destruidos o clausurados por la construcción de los grandes túmulos del período Orientalizante. Habla en favor de esta hipótesis la presencia de algunas cerámicas halladas en los niveles de relleno del Túmulo A (Aubet 1975: fig. 58), varios útiles de bronce y de piedra pulimentada localizados en la zona de la necrópolis (Figs. 5 y 6), la presencia de una estela del Bronce final (Aubet 1997) y, por último, el hallazgo de cistas dolménicas y fosas de inhumación localizadas en los años veinte en los Túmulos I y F. Tanto las cerámicas mencionadas como las cistas de los Túmulos E, F e I sugieren la posibilidad de una reutilización en el Hierro de un sector de enterramientos del Bronce, cuyas prácticas funerarias desconocemos. De confirmarse, este fenómeno reflejaría una extraordinaria continuidad en el uso del espacio funerario durante muchas generaciones. El paisaje funerario sería, de este modo, una réplica de lo que se observa en el asentamiento de la Mesa de Setefilla (Aubet, Serna, Escacena \& Ruiz 1983).

A continuación se dan a conocer los materiales de la nueva sepultura, advirtiendo de antemano sobre la dificultad de fijar con rigurosidad su cronología, dentro de los límites que asignamos a las incineraciones de los Túmulos A y B: los siglos VIII y VII a.C. La ausencia de cerámica con decoración bruñida o de importaciones orientales impide ajustar con mayor precisión su cronología relativa.

\section{TUMBA 1 DEL TÚMULO E:}

1. Fragmentos de urna de gran tamaño, fabricada a mano, de la que se conservan parte del cuello y la carena. Arcilla porosa de color castaño rojo, núcleo acastañado y desgrasante mediano y grueso. Superficie del borde y del cuello con engobe bruñido de color castaño rojo, que contrasta con la carena y el cuerpo del recipiente, sin tratamiento y de superficie muy rugosa. Diámetro del borde, $53 \mathrm{~cm}$ (fig. 2).

2. Fragmentos de un soporte hecho a mano, de arcilla muy grosera color castaño y núcleo negruzco. 


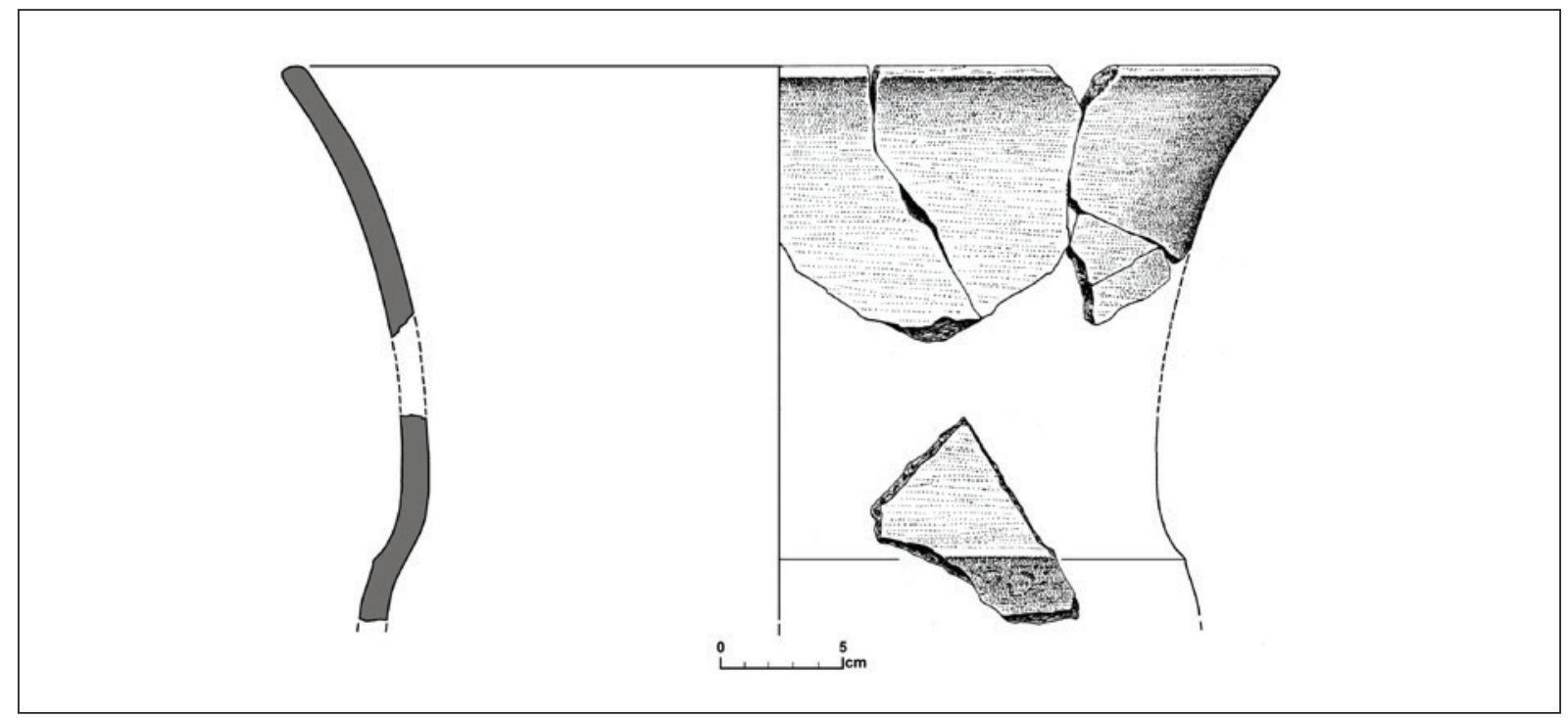

Figura 2. Urna de la tumba $n^{\circ} 1$ del Túmulo E.

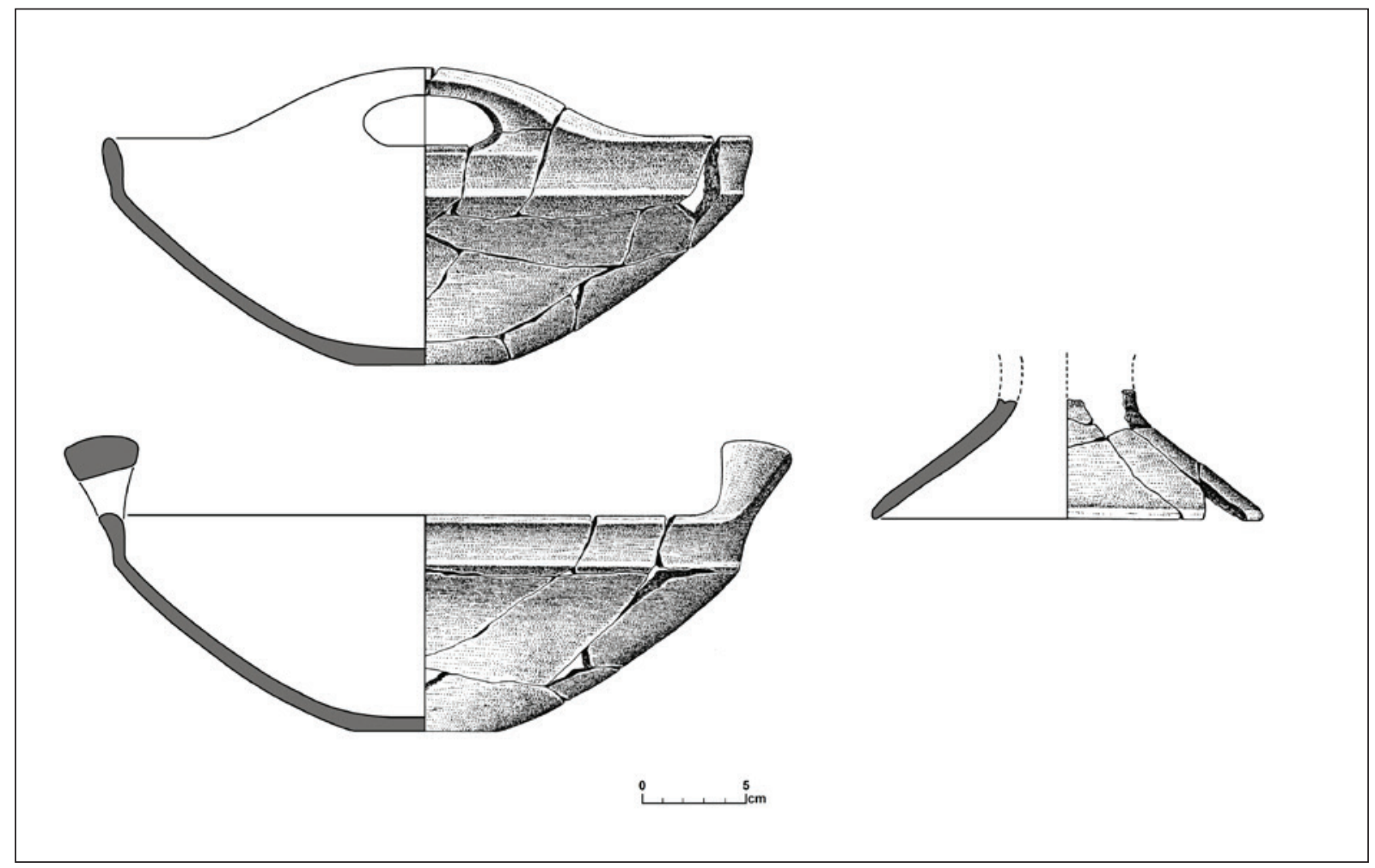

Figura 3. Cuenco y soporte-carrete de la tumba $n^{\circ} 1$ del Túmulo E.

Superficies bruñidas de color castaño negro. Altura máx. 5,8 cm; diámetro de la base, $19 \mathrm{~cm}$ (fig. 3).

3. Cuenco con asas fabricado a mano, incompleto y fragmentado. Arcilla porosa castaño rojiza, desgrasante mediano y fino. Superficie interna bruñida de color negruzco, exterior también bruñido de color castaño negro. Diámetro, 31,6 cm; altura del cuenco, 11,2 cm; con las asas, 14,6 cm (fig. 3). 


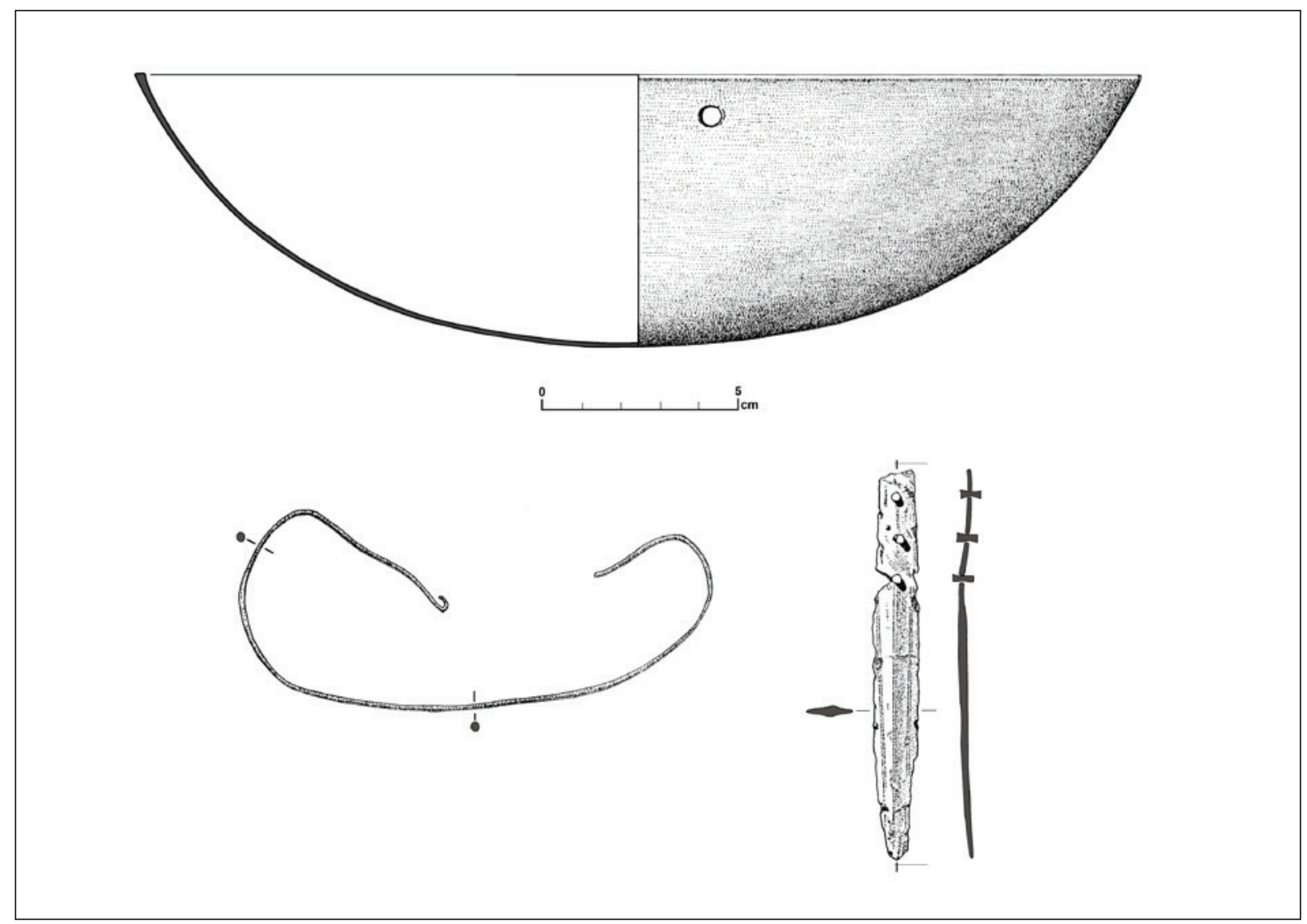

Figura 4. Cuenco, brazalete y puñal de bronce del Túmulo E.

4. Cuenco semiesférico de bronce, de conservación íntegra, aunque con leves fracturas en el borde. Fabricado sobre una lámina de bronce de $0,1 \mathrm{~cm}$ de grosor, salvo en el borde, donde la lámina tiende a engrosarse. Presenta un pequeño orificio cerca del borde. Altura, $6,8 \mathrm{~cm}$; diámetro, 25,7 cm (fig. 4; lám. I).

5. Cuchillo de bronce provisto de tres remaches en la empuñadura. Bien conservado, presenta en ambas caras de la hoja una decoración de tres dobles líneas verticales, muy tenues, que convergen en la punta. Longitud, 9,8 cm; anchura máx., 1,1 cm; grosor máx. de la hoja, 2 cm (fig. 4; lám. II).

6. Brazalete (?) fabricado en hilo de bronce de sólo $0,15 \mathrm{~cm}$ de grosor, terminado en extremos en forma de gancho, de los que sólo se conserva uno. De sección cilíndrica, el grosor del alhambre disminuye en los extremos hasta alcanzar los $0,1 \mathrm{~cm}$ Longitud máx., $26,5 \mathrm{~cm}$ (fig. 4; lám. II).

Las características y contenido de la sepultura que damos a conocer aquí se inscriben en el modelo habitual de enterramiento de incineración de la necrópolis de Setefilla. La urna cineraria dispuesta en una pequeña fosa circular excavada en la roca, conteniendo en su interior los restos óseos y pequeños útiles metálicos de adorno -en este caso un brazalete y un puñal- y diversas vasijas y cuencos colocados a su alrededor constituyen una de las constantes que se repiten en ésta y otras necrópolis tartésicas. Cabe hablar, en este sentido, de una fuerte estabilidad y conservadurismo en las prácticas funerarias entre los grupos incineradores de la zona.

En esta sepultura se observa, sin embargo, un salto cualitativo. La cazuela carenada, cuya función es la de contener comida o bien la de servir de tapadera a la urna, ha sido reemplazada por un cuenco metálico de manufactura casi perfecta y que no tiene paralelos conocidos en la necrópolis. Sólo conocemos un caso parecido, el de la tumba $n^{\circ} 65$ del Túmulo $A$, en el que una forma cerámica conocida -la lucerna de una sola mecha- ha sido sustituída por un ejemplar de bronce (Aubet 1980-81: fig.5).

La traducción en metal de un servicio ritual funerario, vinculado por lo general a ritos de comensalidad o 


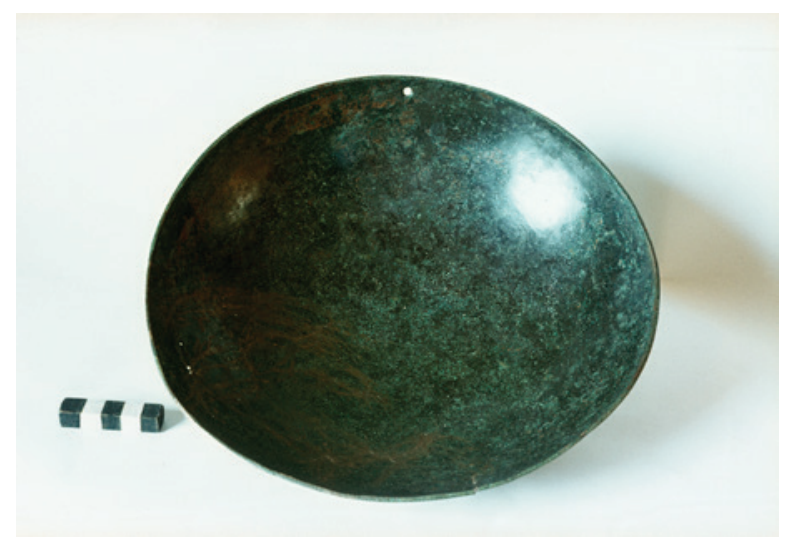

Lámina I. Cuenco de bronce de la tumba 1 del Túmulo E.

a ofrendas de libación, se circunscribe en el área tartésica al ámbito de las denominadas "tumbas principescas" del período Orientalizante. Estas sepulturas se distinguen del resto precisamente por su vajilla en bronce o plata-jarros,lucernas, pebeteros y páteras con asas de manos- que, por regla general, aparecen adsociados a los restos quemados de la pira funeraria. La amortización y destrucción deliberada de estos objetos de lujo en los funerales de los jefes tartesios constituye una de las expresiones más conocidas de ostentación de poder y de prestigio entre las elites locales de La Joya o de Los Alcores de Carmona.

Evidentemente no es éste el caso de la sepultura $\mathrm{n}^{\mathrm{o}} 1$ del Túmulo $\mathrm{E}$ de Setefilla, que en ningún caso cabe integrar dentro de las sepulturas aristocráticas conocidas. Pero sí merece destacarse la presencia del cuenco de bronce, que otorga un cierto status de prestigio a su poseedor y que distingue el contenido de esta sepultura del resto de ajuares funerarios habituales de la necrópolis.

Resulta difícil de establecer la función de este recipiente semiesférico de bronce. En un principio se consideró la posibilidad de que se tratara de un plato de balanza, dadas sus características formales y la escasa profundidad del recipiente. En realidad, sus paralelos más cercanos se encuentran en las balanzas de bronce halladas en sitios levantinos del Hierro, como Hama (Riis 1948:136, fig.181), Megiddo (Guy 1938: lám. 167.3), tumba $n^{\circ} 1$ de Akhziv (Mazar 2004: fig.27), necrópolis occidental de Amathunte (Karageorghis 1984: 915, fig.67) o Palaeopaphos-Skales (Karageorghis 1983:

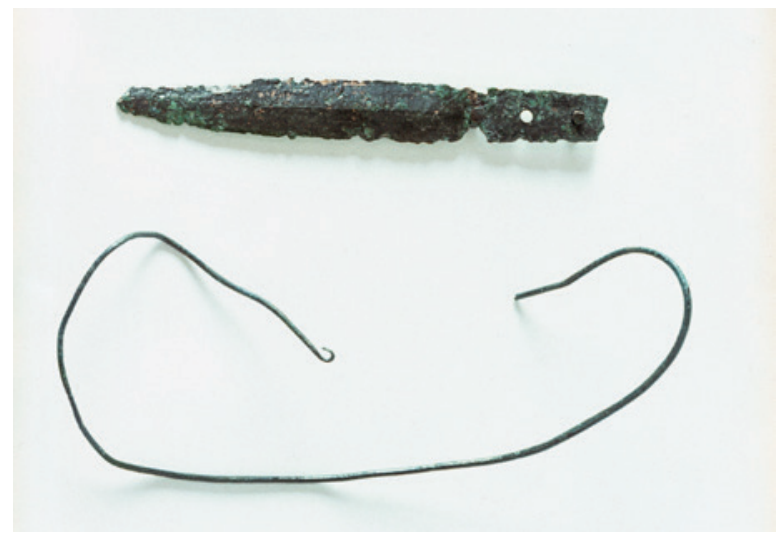

Lámina II. Puñal y brazalete (?) de bronce de la tumba 1 del Túmulo E.

tumbas 48, 49, 50, 67, lám. CXIV, 79 y 80; Courtois 1983: 424). De todos estos paralelos, los ejemplares más parecidos son los de los sitios fenicios de Akhziv y Amathunte. Sin embargo, el diámetro medio de todas estas balanzas no sobrepasa en ningún caso los 10/12 cm. El diámetro del cuenco de Setefilla, de $25,7 \mathrm{~cm}$, es demasiado grande y no corresponde por tanto a la forma habitual de los platos de balanza.

La presencia de un solo orificio en el borde de nuestro recipiente tampoco guarda relación con las balanzas conocidas en Oriente, que casi nunca presentan este tipo de perforaciones. El orificio de nuestro ejemplar sugiere, en cambio, la existencia de un remache y de un enmangue original, probablemente de madera o de otro material orgánico que se ha perdido. Dada la forma semiesférica del cuenco de Setefilla, hay que descartar también que se trate de un espejo.

Todo hallazgo realizado en Setefilla, aun siendo modesto como el de la sepultura $n^{0} 1$ del Túmulo E, contribuye a crear un cuadro de conjunto de las prácticas funerarias tartésicas cada vez más alejado de los esquemas que habíamos trazado tiempo atrás. La presencia de gran número de hallazgos aislados y descontextualizados en el sector de los túmulos (Figs. 5-8), así como un estudio estadístico sobre la variabilidad y distribución de las incineraciones de los Túmulos A y B, actualmente en curso, revelan una compleja organización espacial de grupos de descendencia, en el marco de una comunidad que se manifiesta, en el registro funerario, a través de formas propias de sociedades de transición. 


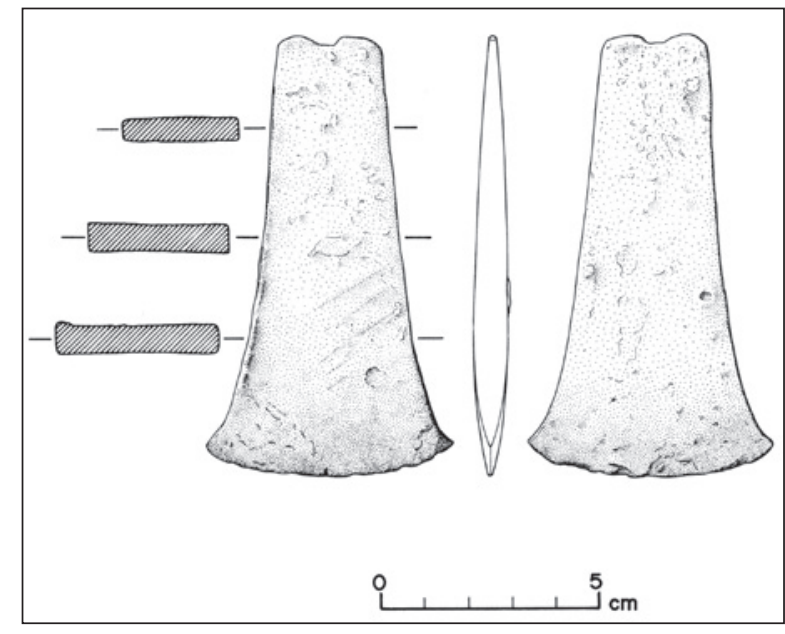

Figura 5. Hallazgos aislados procedentes de la zona de los túmulos de Setefilla: hacha del Bronce Pleno.

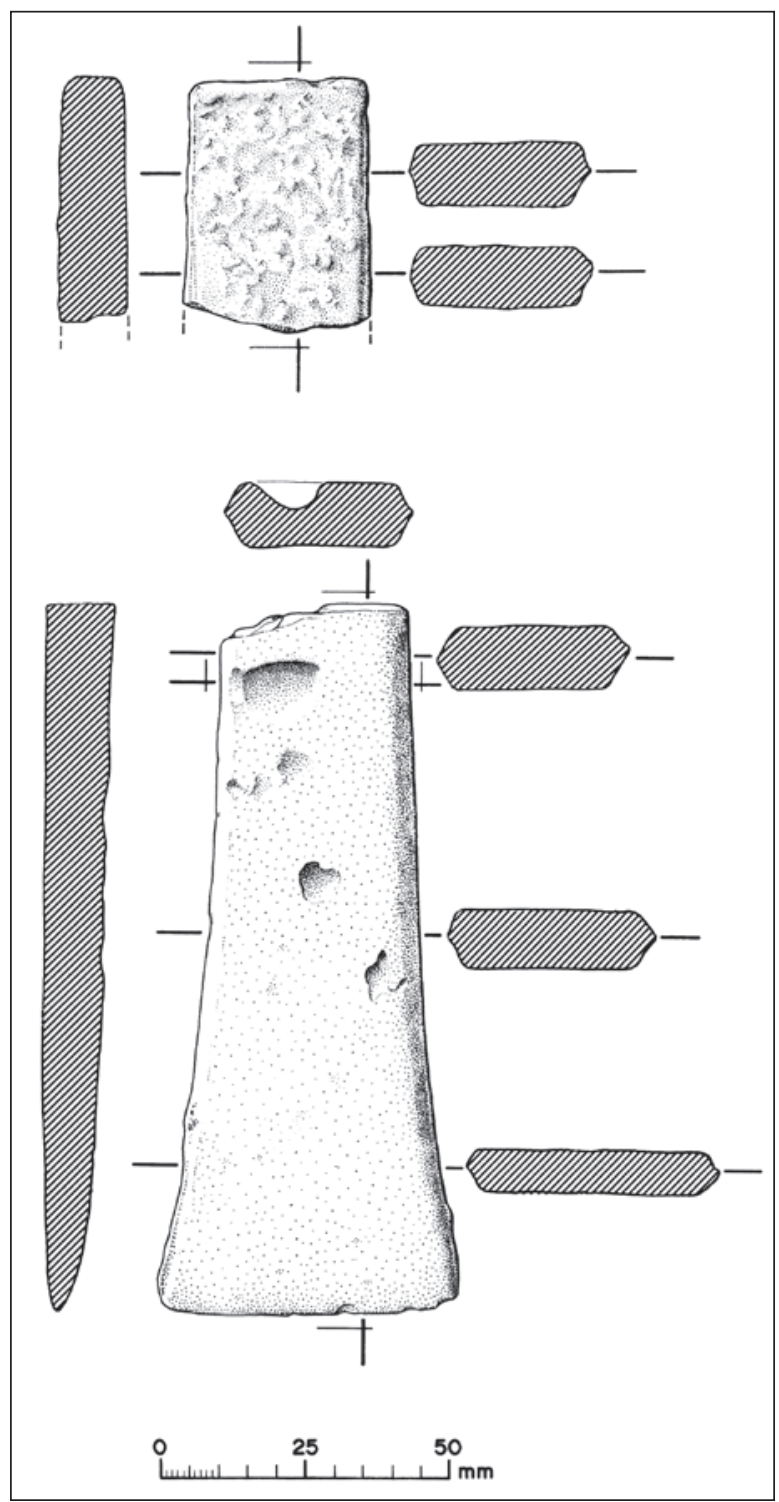

Figura 6. Hallazgos aislados procedentes de la zona de los túmulos de Setefilla: hachas de la Edad del Bronce. 
Figura 7. Hallazgos aislados procedentes de la zona de los túmulos de Setefilla: broches de cinturón tartésicos.
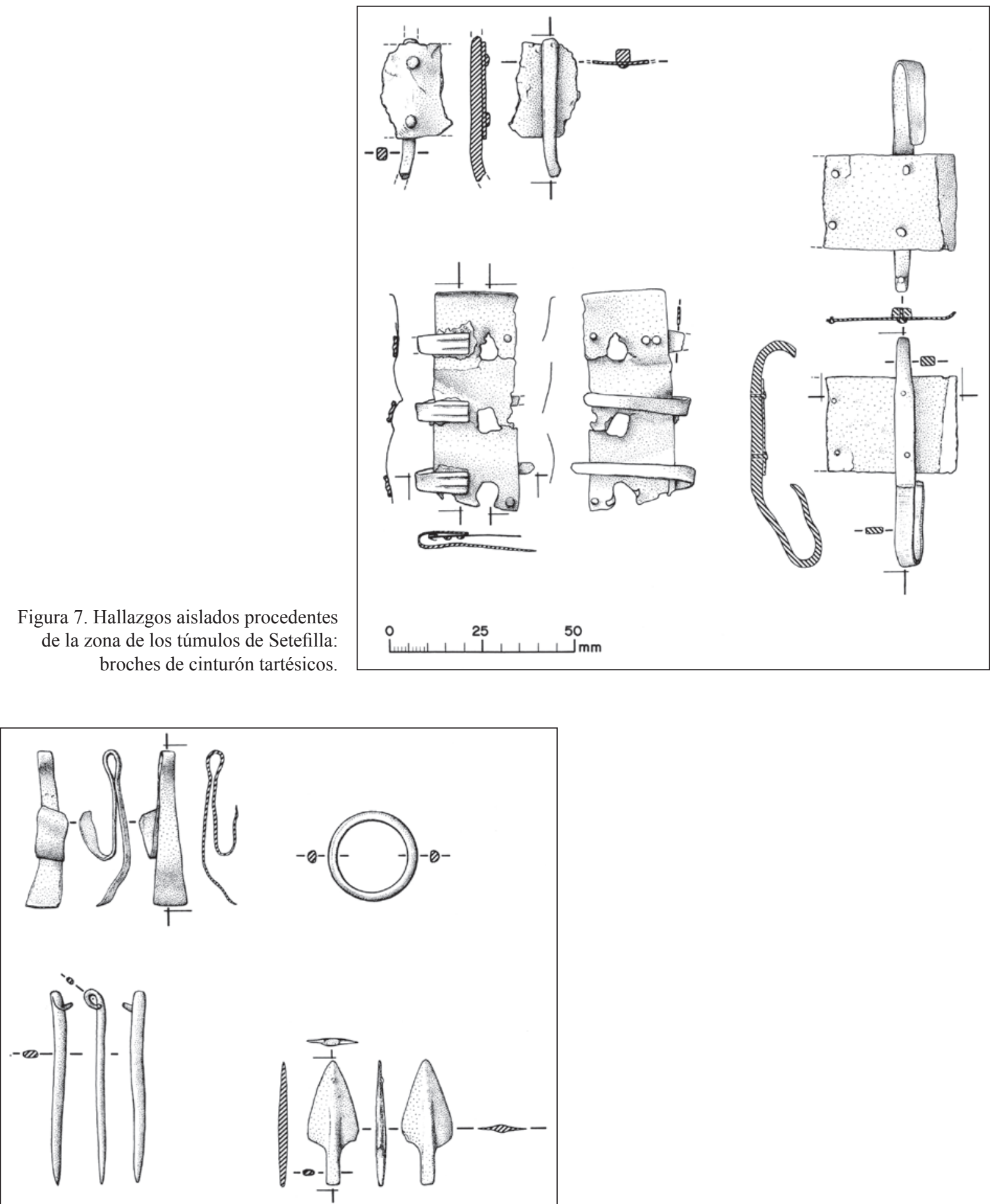

Figura 8. Hallazgos aislados procedentes de la zona de los túmulos de Setefilla: objetos varios de bronce de la época de los túmulos del Hierro. 


\section{BIBLIOGRAFÍA}

AUBET, M.E. (1975): Le necrópolis de Setefilla en Lora del Río (Sevilla), CSIC, Barcelona.

AUBET,M.E. (1978): Le necrópolis de Setefilla en Lora del Río (Túmulo B), CSIC, Barcelona.

AUBET, M.E.; SERNA, M.R.; ESCACENA, J.L. y RUIZ DELGADO, M.M. (1983): La Mesa de Setefilla. Excavaciones Arqueológicas en España 122. Madrid.

AUBET, M.E. (1980-81): "Nuevos hallazgos en la necrópolis de Setefilla”, Mainake II-III: 87-98.

AUBET, M.E. (1997): “A propósito de una vieja estela", Saguntum 30: 163-172.

BONSOR, G.E. \& THOUVENOT, R. (1928): Nécropole ibérique de Setefilla (Lora del Río, Sevilla). Bibliothèque de l'École des Hautes Études Hispaniques XIV, Bordeaux-Paris.

COURTOIS, J.-C. (1983): "Les poids de PalaeopahosSkales", en V. Karageorghis, Palaepaphos-Skales.
An Iron Age Cemetery in Cyprus: 424-425. Ausgrabungen in Alt-Paphos auf Cypern, Bd.3. Universitätsverlag Konstanz.

GUY, P.L.O. (1938): Megiddo Tombs, Oriental Institute Publications 33. The University of Chicago Press. Chicago.

KARAGEORGHIS, V. (1983a): "Chronique des fouilles et découvertes archéologiques à Chypre en 1983", Bulletin de Correspondance Héllénique 108 (2): 893-966.

KARAGEORGHIS, V. (1983b): Palaepaphos-Skales. An Iron Age Cemetery in Cyprus, Ausgrabungen in Alt-Paphos auf Cypern, Bd.3, Universitätsverlag Konstanz.

MAZAR, E. (2004): The Phoenician Family Tomb N.1 at the Northern Cemetery of Achziv (10th-6th Centuries $B C E$ ), Cuadernos de Arqueología Mediterránea 10. Barcelona.

RIIS, P.J. (1948): Hama. Fouilles et recherches 19311938. Fondation Carlsberg. Copenhague.

FECHA DE ENTRADA: 12-11-2010

FECHA DE ACEPTACIÓN: 18-01-2011 